Gut, 1974, 15, 531-544

\title{
Electron microscopic study on the jejunal mucosa in human cholera
}

\author{
HITOSHI ASAKURA, MASAHARU TSUCHIYA, YOONOSUKE WATANABE, \\ YASUHIRO ENOMOTO, AKIRA MORITA, TETSUO MORISHITA, \\ HIDEO FUKUMI, MAKOTO OHASHI, ANTONINA CASTRO, AND \\ CEZAR UYLANOGC
}

From the Department of Internal Medicine and Pathology, School of Medicine, Keio University, Tokyo, Japan, the First Department of Bacteriology, Japanese National Institute of Health, Tokyo, Japan, and The San Lazaro Hospital, Manila, Philippines

SUMMARY Small intestinal mucosa obtained from six fasting patients with cholera by a peroral biopsy technique was studied with the electron microscope. The cultures of their rectal swabs were all positive for Vibrio cholerae. In the absorptive cells, large pseudopod-like cytoplasmic processes with deformed microvilli or without microvilli (blebs) projected into the intestinal lumen from the apical cell surface, interrupting the microvillous border. In the crypts some of the undifferentiated crypt cells possessed pseudopod-like cytoplasmic projections which extended into the crypt lumen. The swelling of mitochondria, the disappearance of their cristae, an increase in the number of vesicles of the Golgi apparatus, and the dilatation and vesiculation of endoplasmic reticulum were observed in the epithelial cells. The apical portion of the cells became oedematous in some of the epithelial cells. Cytoplasmic fragments enclosed by a plasma membrane, desquamated epithelial cells, cytoplasmic organelles, and secretory granules were lying free in the intestinal lumen.

Marked irregular widening of the interepithelial spaces in the jejunal mucoa was observed at the midvillous area. Many cystic vacuoles were present in the cytoplasm of epithelial cells. The possibility of fluids being transported from blood vessels to intestinal lumina through the interepithelial spaces, and the significance of these pathological findings in human cholera are discussed in this study.

The classic or denudation concept of the intestinal lesion in Asiatic cholera was introduced in 1879 by Virchow (1879), who demonstrated in postmortem studies the loss of mucosa from small bowel villi. This denudation concept was denied by Gangarosa, Beisel, Benyajati, Sprinz, and Piyaratn (1960) and by Fresh, Versage, and Reyes (1964) who performed intestinal biopsies in cholera patients. Several experimental models have become available to study the pathogenesis of human cholera, and produce fluid in response to intraluminal instillation of the organism or to intraluminal administration of cholera toxin. It has been shown that an exotoxin produced by Vibrio cholerae induces not only accumulation of intestinal fluid in various experimental animals but also increases in the vascular permeability in the

Authors' address: Department of Internal Medicine, School of Medicine, Keio University, 35 Shinanomachi, Shinjuku-ku, Tokyo, Japan 160.

Received for publication 2 April 1974. mesentery of rat or rabbit (Finkelstein, Nye, Atthasampunna, and Charunmethee, 1966; Tsuchiya, Kamisaka, Oda, Asakura, Ohashi, and Shimada, 1972).

It was reported that no differences were seen by light or electron microscopy between control and experimental animal cholera except for minimal inflammatory changes in the intestinal mucosa (Elliott, Carpenter, Sack, and Yardley, 1970). The observation by Serebro, Iber, Yardley, and Hendrix (1969) that cycloheximide caused morphological changes in the crypts of Lieberkühn led to the hypothesis that the cholera toxin-induced fluid secretion originated from crypt cells. It is surmised that the copious diarrhoea is due to the excessive production of mucus in the crypts of the small intestine as a hypersecretory phenomenon in response to cholera enterotoxin, or to increased movement of water and electrolytes from plasma to the gut lumen through intact cells caused by the 
enterotoxin, which is supposed to increase c-AMP levels by stimulation of adenylcyclase in the mucosal epithelial cells (Carpenter, 1971).

A light microscopic study reported by us on the jejunal mucosa in human cholera showed that there were villi associated with pathological desquamation and necrosis of epithelial cells between villi with intact structures (Asakura, Morita, Morishita, Tsuchiya, Fukumi, Ohashi, Uylangco, and Castro, 1973). Rice watery stool was supposed to be due in part to multiple pathological desquamation and necrosis of the intestinal epithelium, as well as to hypersecretion of epithelial cells and excessive production of mucus in the crypts. It might be supposed that these epithelial abnormalities and secretion by the epithelial cell play a significant role in the production of fluid. However, there are some investigators who suspect these epithelial alterations in artificial or in chronic inflammatory changes.

In order to clarify the mechanism of diarrhoea in man exposed to cholera, small intestinal mucosa obtained from six patients with cholera by peroral biopsy technique was studied with the electron microscope.

\section{Materials and Methods}

Biopsy specimens were obtained under fluoroscopic control (instrument from Shimazuseisaku Co, Japan) by the peroral biopsy technique of Crosby and Kugler (1957) from six cholera patients who were admitted to San Lazaro Hospital (Manila) in 1971 and fasted overnight. The clinical diagnosis was confirmed bacteriologically in each case, and the cultures of rectal swabs were all positive for Vibrio cholerae. The identity of isolates was reported in detail in our previous report (Asakura et al, 1973).

Clinical features of cholera patients and the day of

\begin{tabular}{|c|c|c|c|c|c|c|}
\hline & \multicolumn{6}{|c|}{ Case No. } \\
\hline & 1 & 2 & 3 & 4 & 5 & 6 \\
\hline & M.O. & R.V. & D.A. & C.E. & A.R. & R.V. \\
\hline Age & 46 & 30 & 24 & 35 & 32 & 28 \\
\hline Sex & f & $\mathbf{m}$ & m & $\mathbf{m}$ & f & $\mathbf{m}$ \\
\hline Diarrhoea & + & + & + & + & + & + \\
\hline Rice watery stool & - & + & - & + & - & - \\
\hline Vomiting & + & + & + & - & + & + \\
\hline Abdominal pain & + & - & - & + & - & - \\
\hline Muscle cramps & - & - & - & + & + & + \\
\hline Signs of dehydration & + & + & + & + & + & + \\
\hline $\begin{array}{l}\text { Total stool volume in litres } \\
\text { Vibrio cholerae in rectal }\end{array}$ & 4 & 6 & $\star$ & 5 & 8 & 5 \\
\hline $\begin{array}{l}\text { swabs } \\
\text { Day of illness when biopsy }\end{array}$ & + & + & + & + & + & + \\
\hline was carried out & 2nd & 3rd & 3rd & 4th & 6th & 2nd \\
\hline
\end{tabular}

Table Clinical features of cholera patients

${ }^{2}$ Total stool volume in $\mathbf{2 4}$ hours after admission. $\star$ stool volume was not measured. illness when biopsy was carried out are summarized in the table. Patients had diarrhoea at the time of biopsy but they were not in shock because they were receiving replacement therapy of fluids and electrolytes.

After the biopsy instrument was triggered in the jejunal portion of the intestine under the fluoroscope, it was withdrawn as rapidly as possible. Soon after the specimens thus obtained were gently removed from the capsule they were divided into three portions. One portion was fixed in neutral buffered $10 \%$ formalin and paraffin sections were stained with haematoxylin and eosin for histological examination. For ultrastructural studies, another portion was immediately fixed in ice-cold $2.5 \%$ glutaraldehyde and the other portion was immediately fixed in icecold $1 \%$ phosphate-buffered osmic acid. After dehydrating the specimens in alcohol, small strips of mucosa were embedded in Epon 812. Ultrathin sections were stained with lead nitrate and uranyl acetate and examined with a JEM 100-B electron microscope.

\section{Results}

In several absorptive cells at the midvillous area as well as in undifferentiated crypt cells, large, pseudopod-like cytoplasmic processes(blebs) project into the intestinal lumen from the apical cell surface, interrupting the microvillous border. These pseudopodlike processes contain cytoplasmic organelles, including ribosomes and a cytoplasmic matrix and have no microvilli (figs 1 and 2). Cytoplasmic fragments unattached to cells and enclosed by a plasma membrane are lying free in the intestinal lumen. These unattached cytoplasmic fragments contain the same cytoplasmic materials as those seen in the apical cytoplasmic projections (fig 3).

In the intestinal crypt many undifferentiated cells have membrane-bound secretory granules. The undifferentiated cells possess pseudo-like cytoplasmic projections which extend into the crypt lumen. Many membrane-bound cytoplasmic fragments, many secretory granules, mitochondria, vesicles, and the necrotic cells lie free in crypt lumen (fig 4). Goblet cells which have lost their mucous granules are found.

A second type of large pseudopod-like cytoplasmic processes projects into the intestinal lumen from the apical cell surface of the absorptive cells at the midvillous area, interrupting the microvillous border. In these processes, the cytoplasm has an abundance of small granules like free ribosomes and marked widening of microvilli without normal fine structures. These processes differ in structure from the processes which are described above (fig 5). 


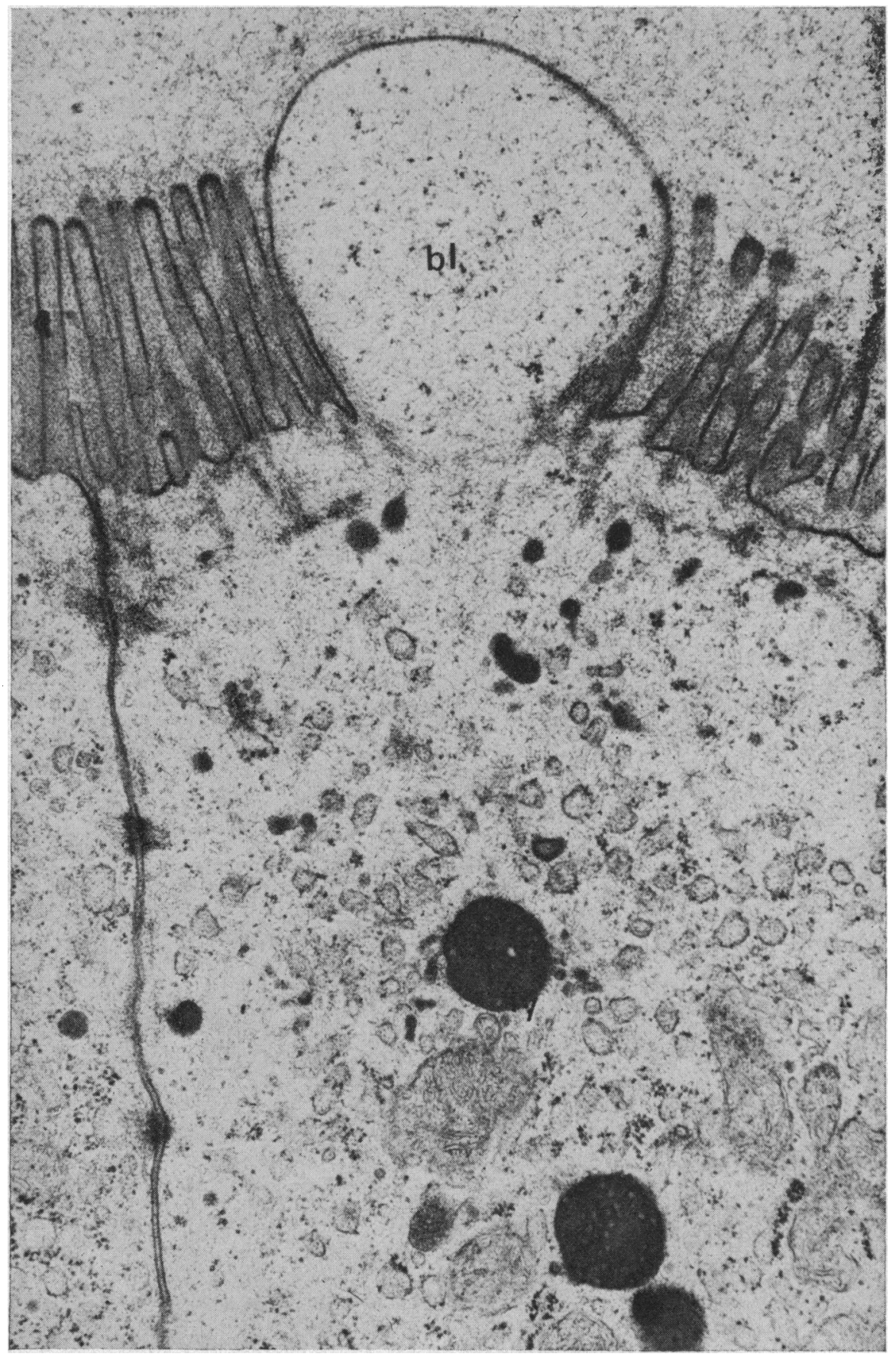

Fig 1 Large bleb (pseudopod-like cytoplasmic process) projects into intestinal lumen from the apical cell surface of absorptive cell. $\times 22000$ 


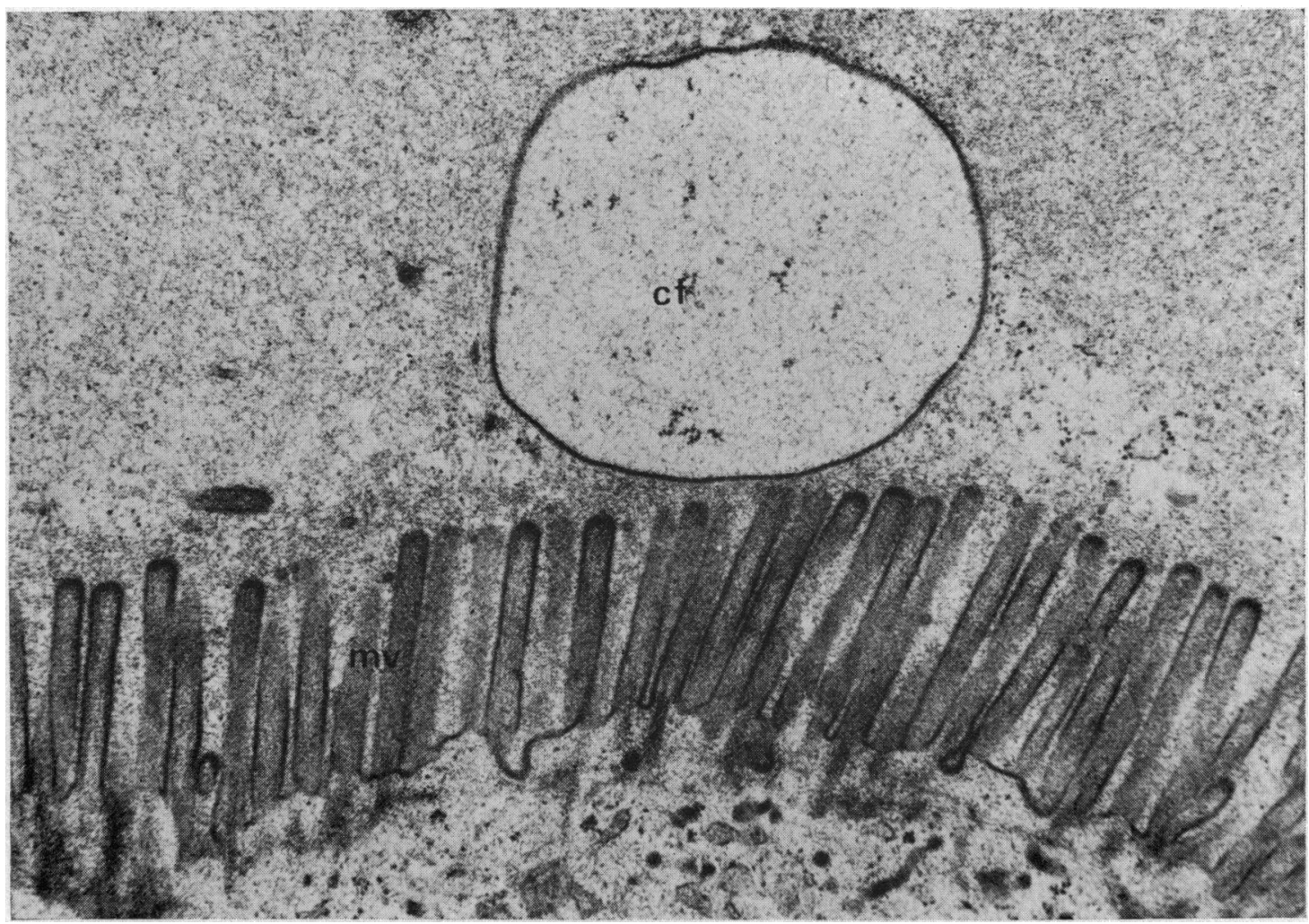

Fig 3 Cytoplasmic fragment unattached to cell and enclosed by a plasma membrane is lying in the intestinal lumen. Microvillous border is not distorted. $\times 22000$ cf, cytoplasmic fragment; mv, microvilli.

Changes in the matrix and organelles of the epithelial cells were seen. Mitochondria are swollen and mitochondrial cristae have disappeared from the cytoplasm of absorptive cells. These mitochondria are scattered in the loosening matrix of the absorptive cells (figs 5 and 6). Moreover, these mitochondria and other organelles can be seen lying free in the intestinal lumen as well as in the epithelial cytoplasm(figs 4and 5). In some of theabsorptivecells, smooth endoplasmic reticulum becomes vesicular and dilated. An increase in the amount of vesicular endoplasmic reticulum is shown in epithelial cells (figs 1, 2, 5 and 6), and a marked increase in the number of vesicles of the Golgi apparatus in the supranuclear region of absorptive cells. Several vesicles have many small spherical bodies in their cavities of a density similar to that of fat droplets (fig 6). Some of the endoplasmic reticulum contains similar droplets in spite of the biopsy being taken from a fasting subject. In some of the epithelial cells of the villi the microvilli have partly disappeared and are becoming deformed (figs 4 and 6).
The apical portion of the epithelial cells at the base of villi is becoming oedematous and the cytoplasmic matrix loosened. Fibrils in the cytoplasmic matrix lose their tight connexions and disintegrate. Apical portions form the third type of large blebs. The plasma membrane surrounding the bleb becomes indistinct (fig 7).

In the intestinal specimens, a marked widening of the interepithelial spaces is observed between the adjacent epithelial cells at the midvillous area. This process is irregular and the interepithelial spaces become wider towards the basal portions (fig 8 ). The widening of the interepithelial spaces is most marked between those epithelial cells which have cystic vacuoles. The substances which are present in the interepithelial spaces resemble in size and density those of the cystic vacuoles in the epithelial cytoplasm. The fine structure of the cystic vacuoles in the epithelial cytoplasm differs from that of fat droplets (fig 9). Cystic vacuoles cannot be seen in all of the epithelial cells but in those in which interepithelial spaces show marked widening. Cystic vacuoles are 


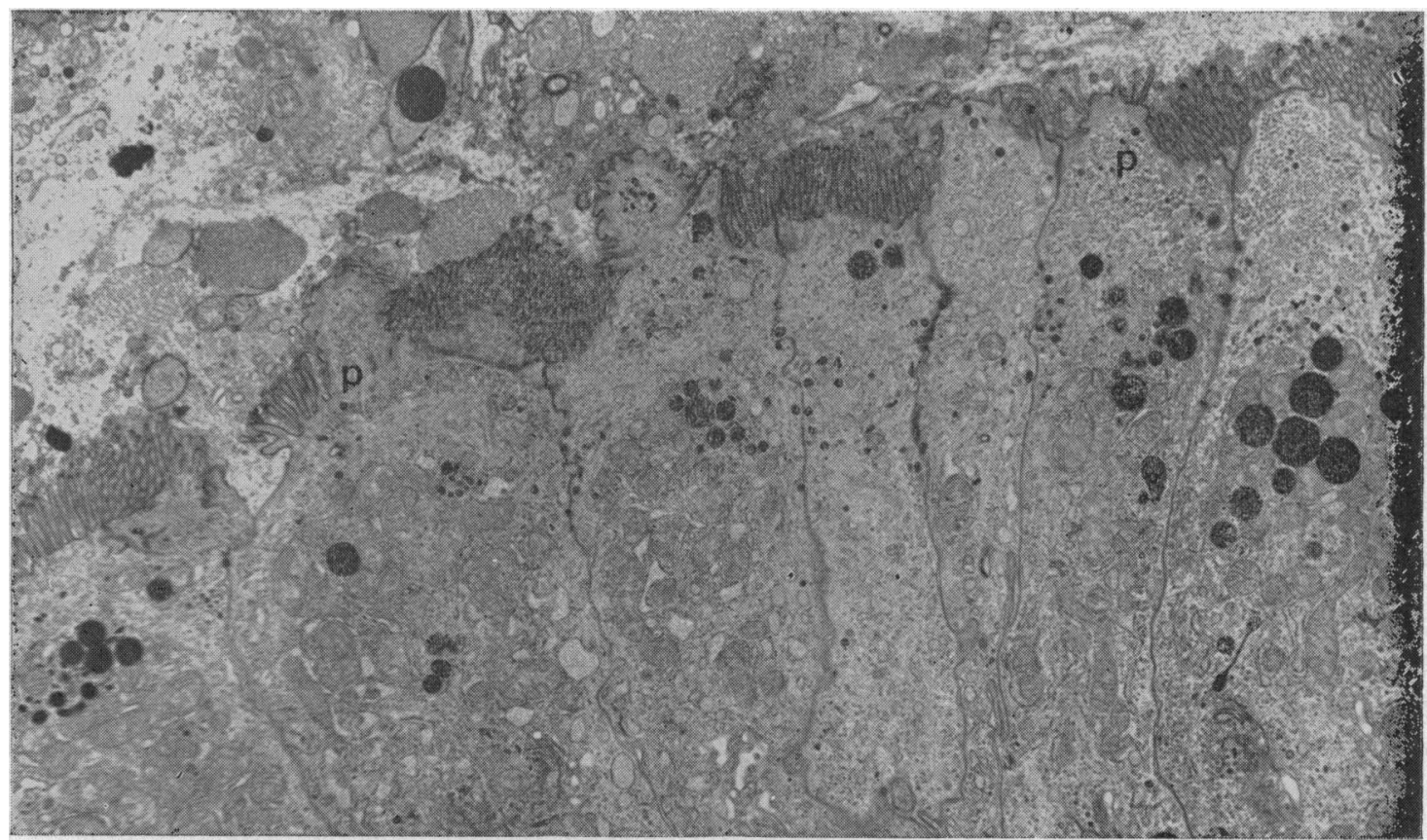

Fig 4 Many crypt cells project pseudopod-like cytoplasmic processes from apical cell surface, interrupting the microvillous border. There are many secretory granules, mitochondria, and vesicles in the intestinal lumen. Some granules have lost their membranes. $\times 5600$ p, process

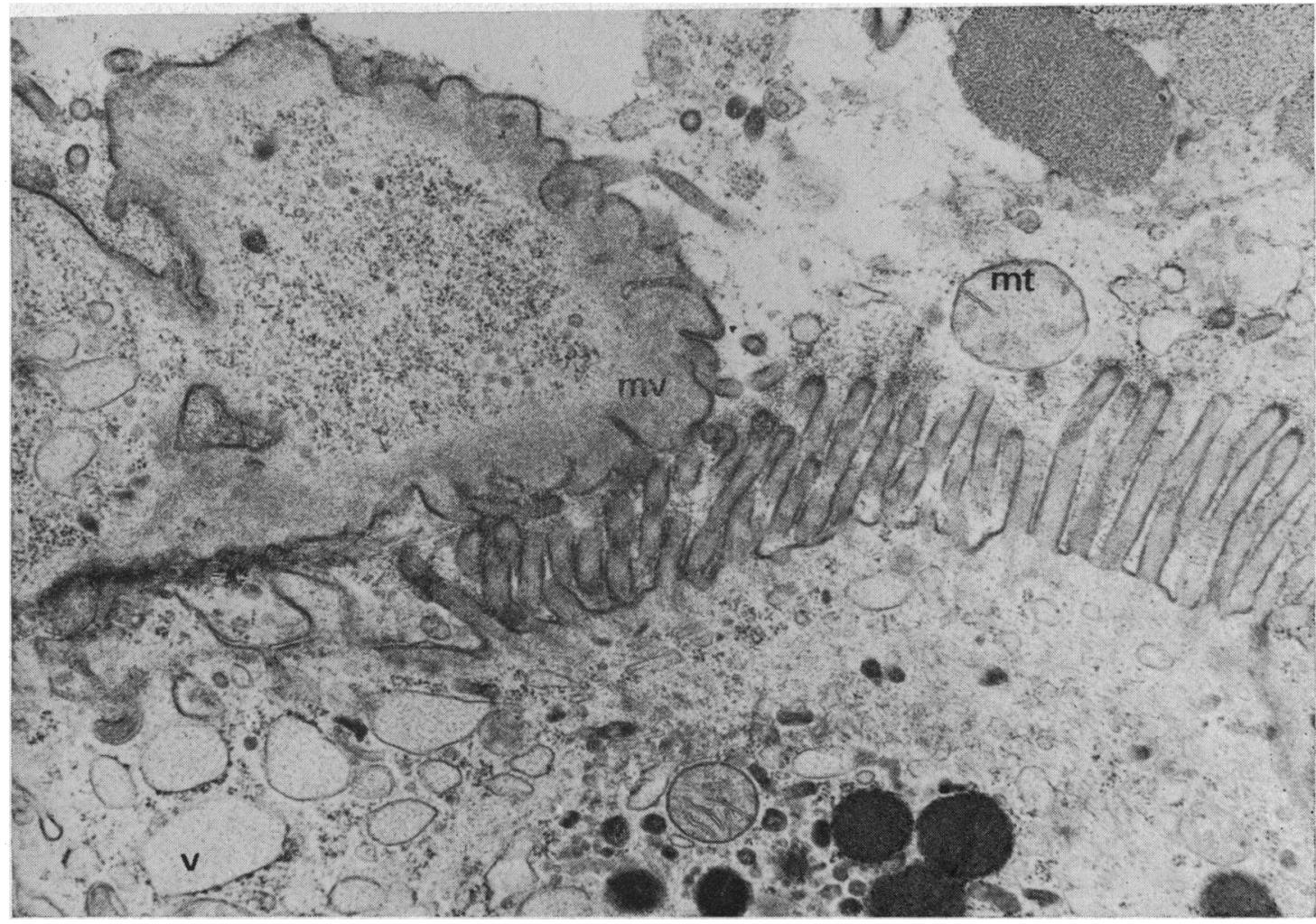

Fig 5 Microvilli are getting wider and disappear. Many vesicles are seen in the apical portion of the epithelial cell. The fuzzy coat has disappeared on some surfaces. There are a few secretory granules, mitochondria, and vesicles in the intestinal lumen. $\times 20000$ $\mathrm{mv}$, microvilli; ml, mitochondria; $\mathrm{v}$, vesicle. 
Fig 6 Deformity and partial disappearance of microvilli are demonstrated. Marked increase in vesicles of the Golgi apparatus is seen in the supranuclear region of absorptive cell. Some vesicles contain spherical bodies (fat droplets). $\times 20000$

g, Golgi apparatus; fd, fat droplets; mv, microvilli 


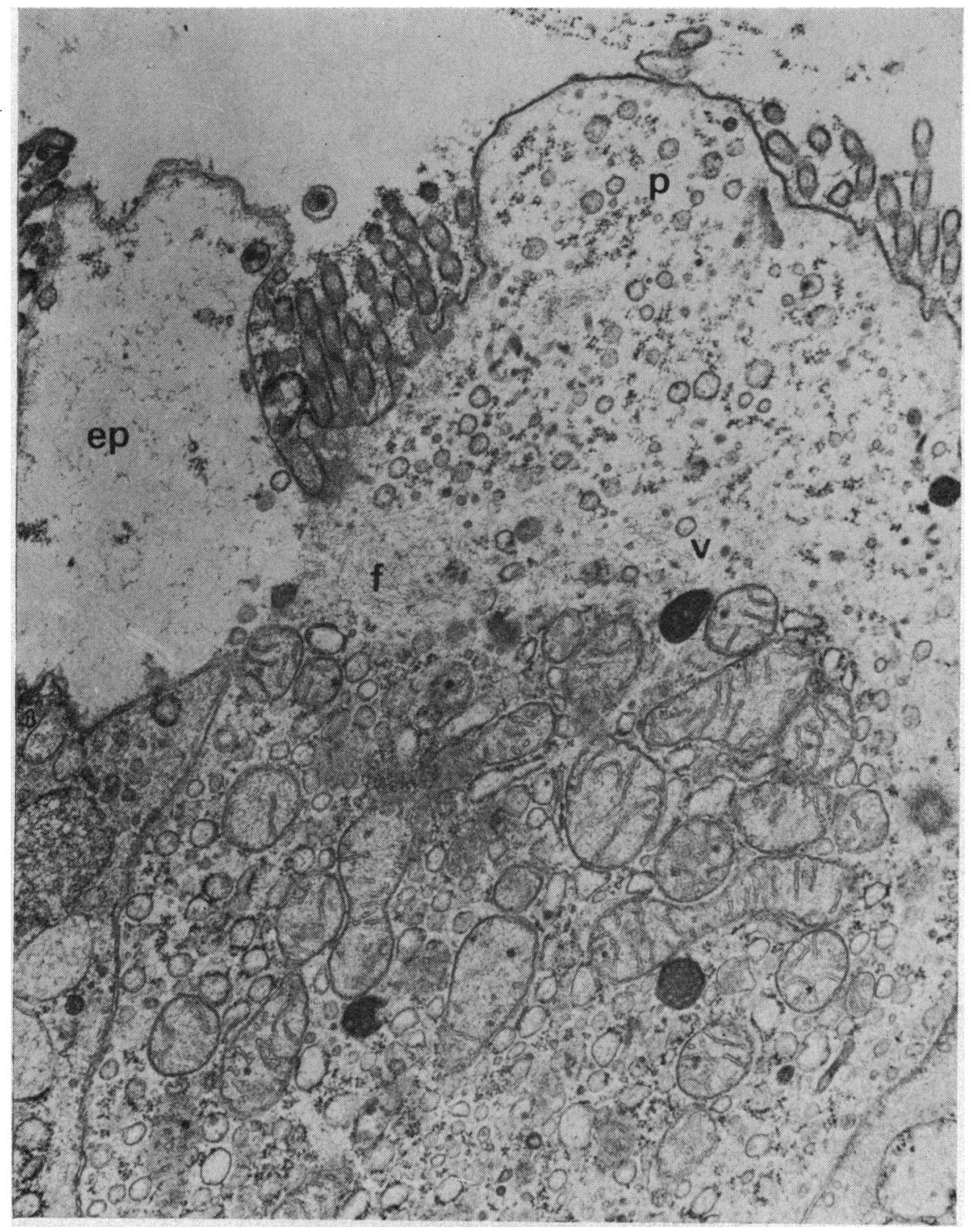

Fig 7 The apical portion of the epithelial cell is oedematous with a loosened cytoplasmic matrix. Fibrils in the cytoplasmic matrix lose their tight connexions and disintegrate. Cytoplasmic projections are being formed at the apical portion. $\times 20000$ $\mathrm{p}$, projection; $\mathrm{ep}$, oedematous projection; $\mathrm{v}$, vesicle; $\mathrm{f}$, fibril

present in the central as well as in the lateral portions of epithelial cells but are not parts of the widened interepithelial spaces.

Loosening of the cytoplasmic matrix and the connexions between their fibrils are seen in scme of the absorptive cells. The terminal web becomes indistinct. The microvillous layer is seen to be broken between adjacent epithelial cells of which the inter- epithelial spaces are particularly wide (fig 9). The tight junctions are above the markedly wide interepithelial spaces. Many mononuclear cells invade the interepithelial spaces. Fluid-like substances similar to those seen in the widened interepithelial spaces are observed in the lamina propria (fig 10), in which blood vessels are not ruptured nor is lymph protein precipitated. 


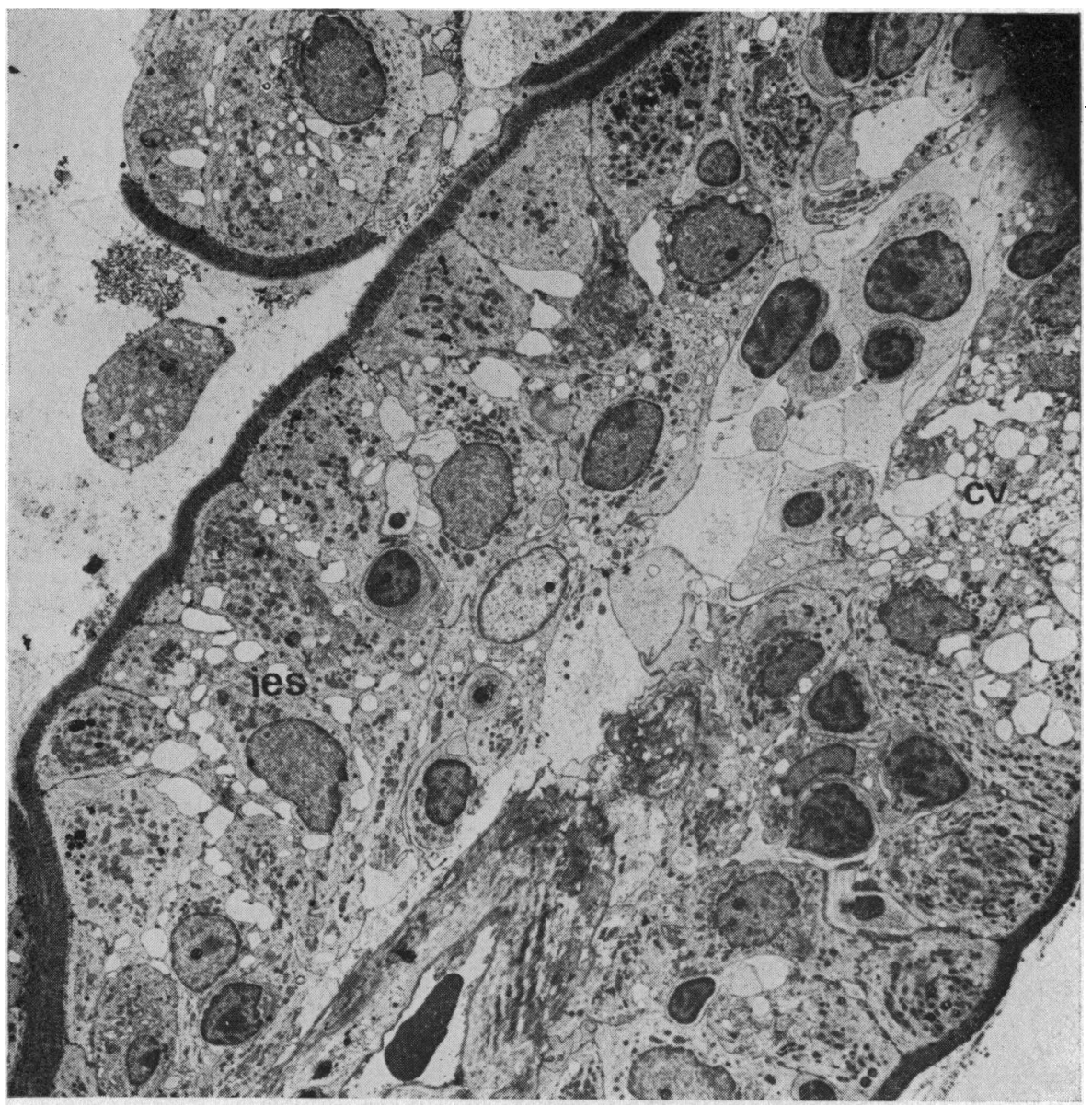

Fig 8 The jejunal epithelial cells and lamina propria of the patient with cholera. Marked widening of the interepithelial spaces and many cystic intraepithelial vacuoles are seen at the mid-villous area. $\times 1600$

ies, interepithial space; cv, cystic vacuole

\section{Discussion}

The classic denudation concept of the intestinal lesion in Asiatic cholera - that a prodigious amount of fluid is lost into the intestinal lumen across denuded villi as in a severe burn-has been disputed for a long time. Today the availability of the peroral biopsy Crosby capsule has made it possible to study the pathology of the gastrointestinal tract without artifacts induced by postmortem changes. The denudation concept has, however, been denied by Gangarosa and Fresh who performed intestinal biopsies in cholera patients. A light microscopic study reported by us on the jejunal mucosa in human cholera disclosed that there were villi associated with pathological desquamation and necrosis of epithelial cells between villi with their structures intact.

Many studies on small bowel morphology in experimental animal cholera have been performed (Patnaik and Ghosh, 1966; Goldstein, Merrill, and Sprinz, 1966; Elliott et al, 1970). Nevertheless, numerous attempts to isolate the moiety of the vibrio responsible for the pathogenic action have been hampered by the paucity of laboratory animals that respond specifically with diarrhoea following enteric challenge. The infant rabbit and suckling mice are. unique in that diarrhoea and dehydration similar to. the human cholera are produced by enteric inoculation of cholera vibrios (Dutta and Habbu, 1955; 


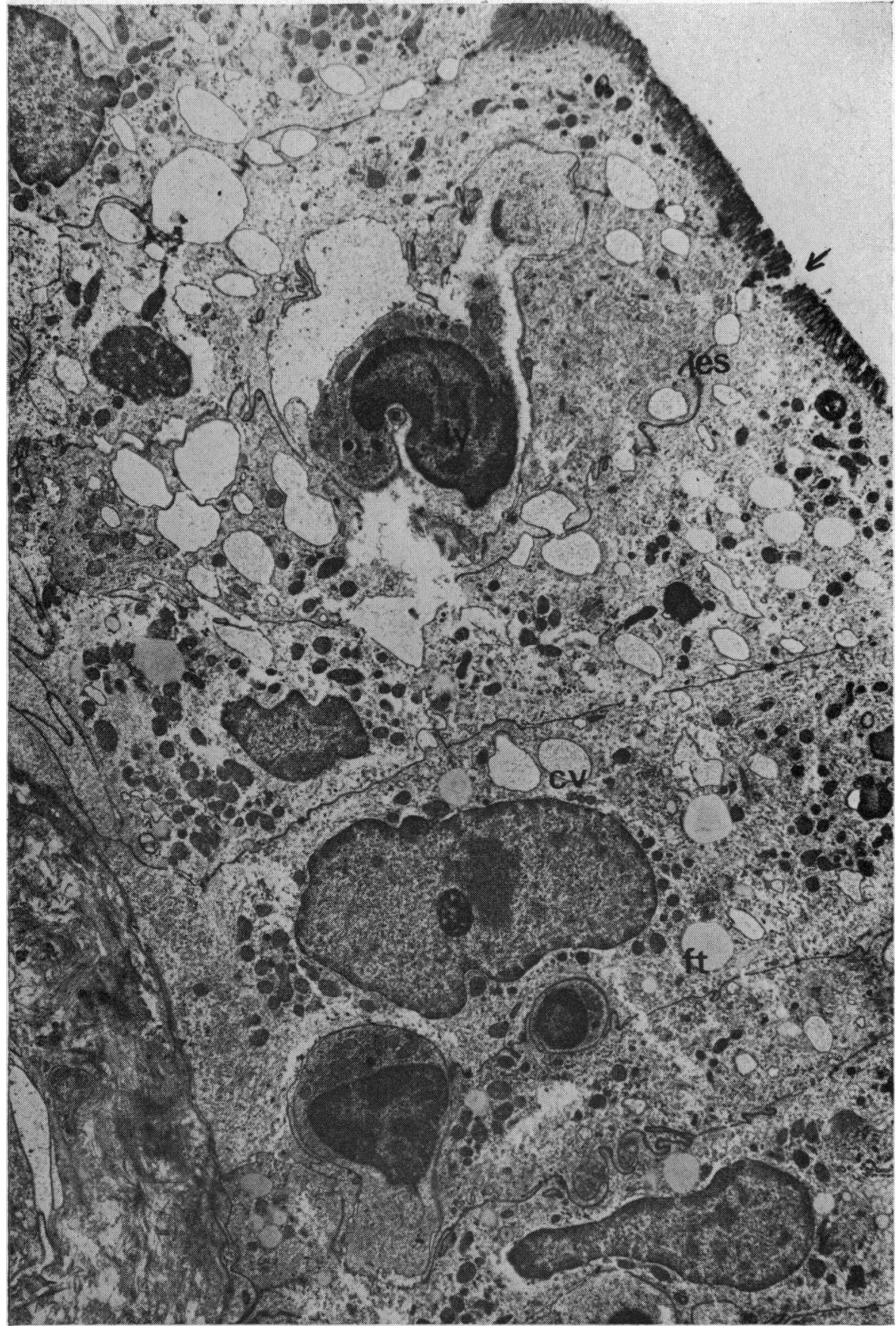

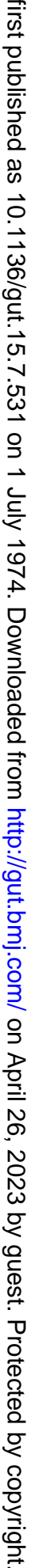

Fig 9 Widened interepithial spaces and cystic vacuoles contain amorphous substances. Fat droplets are seen in spite of biopsy taken from fasting patient. Rupture of microvillous layer is observed between adjacent epithelial cells $(\rightarrow)$. Lymphocytes invade the interepithelial spaces. $\times 4800$ ies, interepithelial spaces; ly, lymphocyte; ft, fat droplet 
Fig 10 Amorphous substances as seen in the widened interepithelial spaces are observed in the lamina propria. $\times 20000$

ec, epithelial cell; ies, interepithelial space; bm, basement membrane; as, amorphous substances; en, endothelium of blood vessel. 
Norris, Finkelstein, Dutta, and Sprinz, 1965). Experimental canine cholera was produced by the administration of a cell-free vibrio culture filtrate as well as by the establishment of a live vibrio infection. The exotoxin has been shown experimentally to act through direct mucosal contact with minimal effects on adjacent isolated intestinal loops not exposed to intraluminal toxins. No differences were seen by light or electron microscopy between controls and experimental animals given cholera except for minimal inflammatory changes in the mucosa (Norris and Majno, 1968; Elliott et al, 1970). Therefore, it is surmised that the copious diarrhoea is due to the excessive production of mucus in the crypts of the small intestine as a hypersecretory phenomenon in response to cholera enterotoxin, or to increased movement of water and electrolytes from plasma to the gut lumen through intact cells caused by the enterotoxin which is supposed to increase c-AMP levels by stimulation of adenylcyclase in the mucosal epithelial cells (Carpenter, 1971; Roggin, Banwell, Yardley, and Hendrix; 1972). Adenylcyclase activity is significantly increased during acute cholera as compared with values during convalescence (Chen, Rohde, and Sharp, 1971). It has been suggested that cyclic AMP may be the intracellular mediator of fluid production in the diarrhoea of cholera. What types of cells are responsible for the increases in c-AMP activity is not clear.

Several pseudopod-like cytoplasmic projections (blebs) were seen on the apical surface of the absorptive cells at the midvillous area in our specimens; these extended into the intestinal lumen and had no microvilli. It has been reported by Trier (Trier, 1964; Trier and Rubin, 1965) that pseudopodlike cytoplasmic projections (blebs) appear on the apical surface of the undifferentiated crypt cells after the injection of pilocarpine. These projections contained a variety of cytoplasmic organelles including membrane-bound secretory granules, ribosomes, strands and vesicles of endoplasmic reticulum, and cytoplasmic matrix. The undifferentiated cells are columnar with basally located nuclei and their microvilli are shorter and less numerous than those on absorptive cells. Many membrane-bound secretory granules are seen in the apical cytoplasm of human undifferentiated cells. However, we found that these projections appeared on the apical surface of the absorptive cells at the midvillous area as well as in the undifferentiated crypt cells.

The second type of pseudopod-like cytoplasmic projections of the undifferentiated crypt cells or the absorptive cells, which contain free ribosomes and have deformed microvilli, have not been reported in any other diseases, including chronic inflammatory diseases.
The third type of large pseudopod-like cytoplasmic processes was observed on the absorptive cells at the base of villi: these differed in their structure from those of the second type and from those seen after the injection of pilocarpine. The apical portion of the epithelial cells was found in oedematous conditions in which the cytoplasmic matrix was loosened and, it was supposed, formed pseudopod-like processes. The formation of many kinds of pseudopod-like cytoplasmic processes might suggest hyperscretion of the jejunal mucosa in human cholera.

Dilatation and vesiculation of smooth endoplasmic reticulum were observed in the absorptive cells in our specimens. These changes occur when a folic acid antagonist has been given, after abdominal irradiation, or in non-tropical sprue (Padykula, Strauss, Ladman, and Gardner, 1961; Rubin, Ross, Sleisenger, and Weser, 1966; Toner, 1968). It might be disputed whether these alterations indicate increased organelle turnover or are a manifestation of sublethal cell injury. The disappearance of mitochondrial cristae as well as the swelling of mitochondria is a peculiar feature. Its significance remains unknown. It is probable that these changes were not specific for cholera. The Golgi apparatus plays an important role in the absorption, secretion, and accumulation of substances. A marked increase in the number of vesicles of Golgi apparatus should be considered, but there is no evidence available which suggests hypersecretion from the epitheial cell.

This electron microscopic study revealed marked widening of the interepithelial spaces at the midvillous area of the mucosa. The cytoplasmic processes of adjacent epithelial cells' generally interdigitate with one another at their lateral borders in normal specimens, and the upper halves of the lateral plasma membranes of the cells are closely opposed to each other. Between the basal portions of the cells there are relatively large interepithelial spaces which are most prominent at the villous tip and disappear entirely near the base of the villus (Trier, 1964 and 1968). Marked widening of the interepithelial spaces at the midvillous area, as seen in our specimens, has not been demonstrated in any other diseases, including those associated with an atrophic state of the small intestine (Padykula et al, 1961), and is supposed to be specific fur cholera. Widening of the interepithelial spaces in the mucosa may suggest the interepithelial passage of water from venules in the lamina propria into the intestinal lumen in human cholera because patients have not taken any fluids by mouth. It was also shown that the microvillous layer was ruptured between the epithelial cells, but tight junctions were present between them. Yardley and Brown (1973) reported in their study on the intestine of rabbit exposed to choleratoxin that horseradish 
peroxidase administered intravenously did not reach the lumen beyond the tight junction, but water might pass through it from the interepithelial spaces into the intestinal lumen.

There were many cystic vacuoles in the epithelial cytoplasm which contained abundant fluid. The origins of these vacuoles are unknown. Substances in these vacuoles differed in their structure and density from fat droplets in the epithelial cells and from chylomicrons in the interepithelial spaces, which appeared after the ingestion of peanut oil. Abnormal vacuoles in the cytoplasm were reported to be present in the abnormal villous epithelium from the patient with idiopathic steatorrhoea (Toner, 1968). But cystic vacuoles in cholera differ in their structure and density from those vacuoles. It is not known whether these vacuoles indicate the degenerative changes of the epithelium, the transport of fluids in the cytoplasm, or the accumulation of some substance produced by endoplasmic reticulum. It is certain that cystic vacuoles have a close relationship with marked widening of interepithelial spaces.

In the lamina propria of the small intestine, the infiltration of many small round cells was observed in our specimens. However, chronic inflammation has been seen in the intestines of people without cholera in Thai (Sprinz, Sribhibhadh, Gangarosa, Benyajati, Kundel, and Halstead, 1962). Dilatation of lymphatic vessels as seen in lymphangiectasia intestinalis and retention of precipitated lymph protein in the lamina propria of villi as seen in protein-losing enteropathy were not demonstrated in our specimens (Waldmann, Steinfeld, Dutcher, Davidson, and Gordon, 1961; Dobbins, 1966). These results may suggest no escape of serum protein and macromolecules into the intestinal cavity in cholera (Gordon, 1962). Many vesicles were seen in the endothelium of blood vessels but rupture of blood vessels was not demonstrated. There were abundant epithelial cells with an intact fine structure.

It may be supposed that the degree of cholera diarrhoea depends on the severity of the epithelial changes and the numbers of epithelial cells which show cytoplasmic alterations. It was reported by Norris (1972) that chronic enterocolitis and fatty metamorphosis of the liver were probably present in Filipinos before the patients developed cholera but we have no report that our findings are similar to those seen in chronic enterocolitis. To clarify the mechanism of diarrhoea in human cholera, many problems provide a challenge for clinical investigation (Sladden, 1973).

The authors wish to acknowledge the cooperation of Dr J. C. Azurin, Director of Quarantine in the Philippines, Dr H. Ogonuki, Officer of the Japanese
OTCA, Dr Y. Inaba, a member of the Japanese OTCA, and the doctors, nurses, and helpers at the San Lazaro Hospital.

\section{References}

Asakura, H., Morita, A., Morishita, T., Tsuchiya, M., Fukumi, H., Ohashi, M., Uylangco, C., and Castro, A. (1973). Pathologic findings from intestinal biopsy specimens in human cholera. Amer. J. dig. Dis., 18, 271-279.

Carpenter, C. C., Jr., (1971). Cholera enterotoxin: recent investigations yield insights into transport processes. Amer. J. Med. 50, 1-7.

Chen, L. C., Rohde, J. E., and Sharp, G. W. G. (1971). Intestinaadenylcyclase activity in human cholera. Lancet, 1, 939-941.

Crosby, W. H., and Kugler, H. W. (1957). Intraluminal biopsy of the small intestine. Amer. J. dig. Dis., 2, 236-241.

Dobbins, W. O. (1966). Electron microscopic study of the intestinal mucosa in intestinal lymphangiectasia. Gastroenterology, 51, 1004-1017.

Dutta, N. K., and Habbu, M. K. (1955). Experimental cholera in infant rabbits: a method for chemotherapeutic investigation. Brit. J. Pharmacol., 10, 153-159.

Elliott, H. L., Carpenter, C. C. 'J., Sack, R. B., and Yardley, J. H. (1970). Snsall bowel morphology in experimental canine cholera. Lab. Invest., 22, 112-120.

Finkelstein, R. A., Nye, S. W., Atthasampunna, P., and Charunmethee, D. (1966). Pathogenesis of experimental cholera: effect of choleragen on vascular permeability. Lab. Invest., 15, 1601-1609.

Fresh, J. W., Versage, P. M., and Reyes, V. (1964). Intestinal morphology in human and experimental cholera. Arch. Path., 77, 529-537.

Gangarosa, E. J., Beisel, W. R., Benyajati, C., Sprinz, H., and Piyaratn, P. (1960). The nature of the'gastrointestinal lesion in Asiatic cholera and its relation to pathogenesis: a biopsy study. Amer. J. trop. Med., 9, 125-135.

Goldstein, H. B., Merrill, T. G., and Sprinz, H. (1966). Experimental cholera. Arch. Path., 82, 54-59.

Gordon, R. S., Jr. (1962). The failure of Asiatic cholera to give rise to 'exudative lenteropathy'. In SEATO Conference on Cholera, 1960, SEATO, Bangkok, p. 54.

Norris, H. T. (1973). Changing pattern of autopsy findings in patients dying of cholera after 1960. Amer. J. trop. Med., 22, 215-222.

Norris, H. T., Finkelstein, R. A., Dutta, N. K., and Sprinz, H. (1965). Intestinal manifestations of cholera in infant rabbits: a morphologic study. Lab. Invest., 14, 1428-1436.

Nerris, H. T., and Majno, G. (1968). On the role of the ileal epithelium in the pathogenesis of experimental cholera. Amer. J. Path., 53, 263-279.

Padykula, H. A., Strauss, E. W., Ladman, A. J., and Gardner, F. H. (1961). A morphologic and histochemical analysis of the human jejunal epithelium in nontropical sprue. Gastroenterology, 40, 735-765.

Patnaik, B. K., and Ghosh, H. K. (1966). Histopathological studies on experimental cholera. Brit. J. exp. Path., 47, 210-214.

Roggin, G. M., Banwell, J. G., Yardley, J. H., and Hendrix, T. R. (1972). Unimpaired response of rabbit jejunum to cholera toxin after selective damage to villus epithelium. Gastroenterology, 63, 981-989.

Rubin, W., Ross, L. L., Sleisenger, M. H., and Weser, E. (1966). An electron microscopic study of adult celiac disease. Lab. Invest., 15, 1700-1747.

Serebro, H. A., Iber, F. L., Yardley, J. H., and Hendrix, T. R. (1969). Inhibition of cholera toxin action in the rabbit by cycloheximide. Gastroenterology, 56, 506-511.

Sladen, G. E. (1973). The pathogenesis of cholera and some wider implications. Gut, 14, 671-680.

Sprinz, H., Sribhibhadh, R., Gangarosa, E. J., Benyajati, C., Kundel, D., and Halstead, S. (1962). Biopsy of small bowel of Thai people. Amer. J. clin. Path., 38, 43-51.

Toner, P. G. (1968). Cytology of intestinal epithelial cells. Int. Rev. Cytol., 24, 233-343.

Trier, J. S. (1964). Studies on small intestinal crypt epithelium. II Evidence for and mechanisms of secretory activity by undifferentiated crypt cells of the human small intestine Gastroenterology, 47, 480-495. 
Trier, J. S. (1968). Morphology of the epithelium of the small intestine. In Handbook of Physiology. Sect. 6, Alimentary Canal, Vol. III. Intestinal Absorption, edited by C. F. Code and W. Heidel, pp. 1125-1175. Williams and Wilkins, Baltimore.

Trier, J. S., and Rubin, C. E. (1965). Electron microscopy of the small intestine: a review. Gastroenterology, 49, 574-603.

Tsuchiya, M., Kamisaka, Y., Oda, M., Asakura, H., Ohashi, M., and Shimada, T. (1972). Effect of cholera toxin on vascular permeability and mast cells. Biochem. exp. Biol., 10, 107-113.
Virchow, R. (1879). Gesammelte Abhandlungen auf dem Gebiete der. offentlichen Medizin, Vol. 1, p. 151. Hirschwald, Berlin.

Waldmann, T. A., Steinfeld, J. L., Dutcher, T. F., Davidson, J. D. and Gordon, R. S., Jr. (1961). The role of the gastrointestinal system in idiopathic hypoproteinemia. Gastroenterology, 41, 197-207.

Yardley, J. H., and Brown, G. D. (1973). Horseradish peroxidase tracer studies in the intestine in experimental cholera. Lab Invest., 28, 482-493. 